\title{
Experiências de usos do Facebook como estratégia de ensino de jornalismo digital
}

\author{
Adriana Amaral \\ Universidade do Vale do Rio dos Sinos - adriana.amaral08@gmail.com \\ Professora do Programa de Pós-Graduação em Ciências da Comunicação \\ da Unisinos e dos cursos de graduação em Jornalismo e Comunicação Digital. \\ É pesquisadora do CNPq. É jornalista e doutora em Comunicação Social pela PUCRS. \\ CAMILA KeHL \\ Universidade do Vale do Rio dos Sinos - milakehl@gmail.com \\ Estudante de Jornalismo da Unisinos e Bolsista de Iniciação Científica \\ Pibit/FAPERGS (Fundação de Amparo à Pesquisa do Estado do Rio Grande do Sul)
}

\section{Resumo}

Este artigo apresenta experiências de uso do Facebook como estratégia de ensino de jornalismo digital no contexto da cibercultura, tendo a apropriação da ferramenta Grupos em sala de aula como objeto de análise. Resgatamos discussões teóricas sobre o ensino de jornalismo digital no Brasil e depois partimos para a observação empírica da criação do Grupo Jornalismo Online I Segundas Feiras - construído e utilizado dentro da disciplina na graduação em Jornalismo da Unisinos. Como resultados iniciais, sistematizamos quatro tipos de apropriação: mural de recados; postagem de links de notícias e informações relativas aos conteúdos da disciplina; para envio dos trabalhos produzidos em aula e como forma de conversação informal entre os alunos e a professora. Esses usos contribuem e ampliam possibilidades de vivência teóricoprática das principais competências requeridas para ensino e aprendizagem do jornalismo digital.

\section{Palavras-chave}

Cibercultura. Ensino de Jornalismo Digital. Facebook.

\begin{abstract}
This paper is about the experiences and uses of Facebook as an strategy for teaching digital journalism in cyberculture context, while the Groups feature was used as our object of research. In order to analyze this object, first we've focused on the theoretical discussions about teaching digital journalism in Brazil; secondly we've shifted our attention to the experience of creating and using de group Jornalismo Online I Segundas Feiras - a group created on the Online Journalism I Course from the Journalism undergraduation course at Unisinos. From the grounde theory approach we've watched four kinds of uses of this group feature: as a wall of message open to all the class; for posting hyperlinks with content and infroamtion related to digital journalism field; for sending and showing schoolworks done by the students and for informal conversation between all the class. These uses contribute and amplify possibilities of experiencing theoretical and practical capabilities required for teaching and learning digital journalism.
\end{abstract}

Keywords

Cyberculture. Teaching Digital Journalism. Facebook.

Artigo recebido em 25/03/2012

Aprovado em 05/04/2012 
presente artigo foi escrito em forma mista de relato de experiência e de narrativa de inspiração etnográfica, a partir de duas perspectivas nem sempre convergentes: a do professor e a do alunoi. Assim, além de apresentar procedimentos que articulam o online e o offline em sala de aula, nosso objetivo é relatar essa dupla inserção no ambiente pesquisado: a primeira delas é discorrer sobre a experiência do grupo Jornalismo Online I - 2as Feiras do Facebook ${ }^{i i}$, criado para a disciplina de Jornalismo Online I do curso de graduação em Jornalismo da Universidade do Vale do Rio dos Sinos (UNISINOS) durante o segundo semestre de 2011. A segunda é indicar algumas possibilidades e limitações dos usos do Facebook para o ensino do jornalismo digital, colaborando assim para a expansão da bibliografia e para o compartilhamento de práticas e métodos de ensino sobre a temática.

$\mathrm{O}$ artigo surgiu inicialmente da combinação entre inquietações a respeito de práticas de ensino e experiências cotidianas de docência e pesquisa. A primeira dessas inquietações surgiu de uma observação e de uma dificuldade cotidiana em sala de aula no ano de 2011: ministrar e/ou assistir a uma disciplina de Jornalismo Online num laboratório de informática no qual uma turma de vinte e seis alunos passava a maior parte do tempo da própria aula conectada em sites de redes sociais ${ }^{\mathrm{iii}}$, sobretudo o Facebook $^{\text {iv }}$. Como utilizar em sala de aula uma plataforma em que o ritmo quase frenético das postagens de conteúdos poderia proporcionar um alto grau de dispersão informacional?

A motivação desse desafio inicial deu origem à idéia da criação de um grupo fechado da disciplina no Facebook, que foi utilizado e, ao mesmo tempo, observado durante o segundo semestre de 2011. O relato aqui descrito trata tanto dos usos dessa ferramenta (Grupos) dentro do Facebook quanto da observação dos tipos de apropriação que ocorreram na mesma ao longo da disciplina.

Para tanto, inicialmente contextualizamos o ensino de jornalismo digital no Brasil com o objetivo de inserir essa prática como uma iniciativa de abordar o ensino do jornalismo no contexto da convergência dos meios e dos fenômenos da cibercultura a partir de ações práticas, visando tanto a contribuição da formação profissional e teórica dos estudantes, quanto o debate com os professores e pesquisadores da área. Num 
Estudos em Jornalismo e Mídia - Vol. $9 \mathrm{~N}^{\circ} \mathrm{I}$ - Janeiro a Junho de 2012 ISSNe 1984-6924

segundo momento descrevemos a experiência em si, tratando de alguns limites e possibilidades dessa ferramenta para o ensino de jornalismo digital e suas características como a instantaneidade/atualização contínua, a memória, a hipertextualidade, a multimidialidade, a customização/personalização e a interatividade. (PALACIOS, 2004)

\section{O ensino de jornalismo digital: breves reflexões}

A discussão teórica sobre o ensino de Jornalismo Digital no Brasil iniciou nos anos 90 e tem avançado nesses primeiros anos do século XXI, contudo, ainda possui um pequeno corpus em termo de literatura específica, conforme afirma Machado (2011) no prefácio da coletânea Jornalismo e Convergência: ensino e práticas profissionais, organizada por Cláudia Quadros, Kati Caetano e Álvaro Larangeira. Para o escopo teórico desse artigo ${ }^{v}$, tomamos como referências centrais dois projetos de pesquisa desenvolvidos no âmbito nacional recentemente.

O primeiro deles é o "O ensino de jornalismo na era da convergência tecnológica. Metodologias, Planos de estudo e Demandas Profissionais", iniciativa contemplada com verba do Programa Nacional de Cooperação Acadêmica (Procad), da Coordenação de Aperfeiçoamento de Pessoal de Nível Superior (Capes), que reuniu equipes de pesquisadores da área de jornalismo digital de quatro instituições brasileiras de ensino superior: Universidade Federal da Bahia (UFBA), Universidade de São Paulo (USP), Universidade Federal de Santa Catarina (UFSC) e Universidade Tuiuti do Paraná (UTP). Os resultados dessas pesquisas foram reunidos em artigos apresentados em congressos e em livros como "Jornalismo e convergência: ensino e práticas profissionais", organizado por Claudia Quadros, Kati Caetano e Álvaro Larangeira no início de 2011. Dois seminários foram realizados sobre a temática. O primeiro deles ocorrido em Florianópolis, na Universidade Federal de Santa Catarina (UFSC) em 2010; e o segundo na Universidade Tuiuti do Paraná (UTP) em Curitiba ${ }^{\text {vi }}$.

O segundo projeto norteador ao currículo foi o "Mapeamento do ensino de jornalismo digital no Brasil em 2010”, resultado da pesquisa de oito meses com verba da Lei de Incentivo à Cultura captada pelo Projeto Rumos (Jornalismo Cultural) do 
Instituto Itaú Cultural, de São Paulo. Essa pesquisa foi realizada por professores/pesquisadores, profissionais e estudantes de jornalismo de diversas instituições brasileiras coordenada pelo professor Alex Primo da Universidade Federal do Rio Grande do Sul (UFRGS).

Esses estudos foram essenciais para a compreensão do ensino de jornalismo digital ao nos fornecer pistas e embasamento teórico, além de dados empíricos ao apontar a percepção de que os currículos da maioria dos cursos de jornalismo no Brasil ainda discutiam os processos de convergência dos meios e as questões sobre a digitalização em disciplinas estanques, isoladas de um contexto maior no qual a tecnologia permeia os processos sociais, simbólicos e culturais da sociedade contemporânea. Outro indicativo que apareceu nos resultados dessas pesquisas foi o número restrito de produtos experimentais, de práticas pedagógicas e até mesmo de estratégias de usos desses meios nas próprias disciplinas relacionadas às plataformas digitais nos cursos de jornalismo brasileiro. Ou seja, ainda as experimentações na Universidade ainda são tímidas em relação às possibilidades dos meios e aos produtos desenvolvidos em muitas empresas e suas práticas rotineiras.

Um último apontamento que nos chamou atenção na leitura desses trabalhos foi a falta de relatos que dissequem os processos utilizados pelos docentes para o envolvimento sistemático do aluno com as dinâmicas de produção de conteúdo já adotadas no mercado e na própria rotina dos estudantes. Assim, justificamos a experiência descrita como uma maneira de compartilhar processos de sala de aula que não podem ser desassociados dos processos em curso na sociedade como um todo.

Há razões imperativas para atualizações na formação dos futuros profissionais da imprensa: as práticas, as rotinas produtivas e as teorias jornalísticas passam por transformações que estão relacionadas com as inserções das Tecnologias de Comunicação e Informação (TICs) na sociedade e na cultura. Conforme afirma Machado (2011, p.03), essas transformações antes restritas ao mercado jornalístico chegam à sala de aula e ao cotidiano dos estudantes. Dessa forma, "o uso da tecnologia, que antes era percebido como um movimento tangencial, ainda que cada vez mais relevante, ganha função central no processo de ensino-aprendizagem a partir da 
gradativa disseminação do fenômeno da convergência nos cursos de Jornalismo". (MACHADO, 2011, p.03)

Nesse contexto de incorporação das tecnologias, muitas práticas e rotinas produtivas são repensadas, uma vez que

o fazer jornalístico amplifica-se e torna-se central para a produção de conteúdo da sociedade em rede. Assim, o papel do jornalista como mediador social dos diferentes públicos e informações ganha contornos cada vez mais significativos nas mais diversas plataformas digitais de produção e distribuição de conteúdos. (AMARAL et AL., 2011, p.05).

A presença e os usos de artefatos tecnológicos tais como a internet, sites de redes sociais, blogs, tablets, smartphones e etc, de forma sistemática nas empresas de comunicação e no dia-a-dia dos estudantes - seja em casa, nos estágios, ou na própria universidade - possibilitam uma utilização dos mesmos com fins pedagógicos através de práticas docentes que levem em consideração a centralidade dos mesmos na sociedade atual. Seja para fins profissionais, de busca e recuperação de informações ou para o lazer e o entretenimento, é preciso refletir sobre o ensino e o aprendizado do jornalismo e da cultura digital em seus vários aspectos e desdobramentos com destaque para: as práticas de produção, distribuição e curadoria de conteúdo; os usos e estratégias diferentes para cada tipo de plataforma; a reflexão crítica a respeito dos conteúdos e das linguagens utilizadas e as formas de sociabilidade e interação em fluxo entre os ambientes offline e online.

Tais aspectos demandam observação atenta por parte dos docentes dos movimentos e das práticas culturais empregadas pelos estudantes; assim como, quanto maior o engajamento dos alunos para com o conteúdo discutido em aula maior a expansão e a crítica das práticas realizadas pela área. É a partir desta breve contextualização sobre o ensino do jornalismo digital no contexto brasileiro que partimos para a tarefa de descrever alguns dos usos observados a partir do grupo Jornalismo Online I - 2as Feiras. 


\section{Usos do Facebook na sala de aula de jornalismo digital}

A função "grupos" do Facebook foi criada em outubro de 2010 com o objetivo de unir pessoas selecionadas para a troca privada de informações ${ }^{\text {vii }}$. A ferramenta disponibiliza entre as suas funcionalidades um chat (bate-papo online), compartilhamento de postagens e fotos, além da possibilidade de criação de documentos. A configuração dos grupos pode ser fechada e ter a supervisão de um administrador, o que permite uma maior privacidade no compartilhamento de informações, já que apenas os membros têm acesso às postagens. Nos grupos, a função de notificações de novas postagens acontece da mesma forma em que se apresenta na timeline do perfil pessoal. Ou seja: quando um membro posta uma mensagem, comentário ou utiliza a opção "curtir", todos os demais usuários do grupo irão receber a notificação.

Para fazer uso dessas funcionalidades, durante a disciplina de Jornalismo Online I $^{\text {viii }} 2011 / 2$ do curso de Jornalismo ${ }^{\text {ix }}$, a professora apresentou a proposta de criar um grupo para facilitar a comunicação e a troca de informações com os estudantes, além utilizar a ferramenta como espaço de prática dos conteúdos dados aula. As regras de postagem foram combinadas com os alunos presencialmente pautadas tanto por critérios éticos quanto pelas necessidades específicas do grupo. O grupo Jornalismo Online I 2as Feiras ${ }^{x}$ foi construído na segunda aula do semestre letivo (15 de Agosto de 2011) e foi encerrado somente na última aula (12 de Dezembro de 2012), conforme indicado através do Plano de Ensino.

A primeira postagem do grupo data de sua criação em 15 de agosto de 2011, no qual ele foi descrito como uma ferramenta "que serve para o compartilhamento de links e postagens de materiais referentes à disciplina". O objetivo inicial do grupo até então, previa apenas um dos usos que foram destacados, demonstrando que a apropriação de uma ferramenta depende quase que exclusivamente dos atores sociais. O grupo era fechado e administrado pela professora e pela estagiária-mestranda Lívia Lenz Fonseca $^{\mathrm{xi}}$, e totaliza 29 membros, 289 postagens e 52 documentos criados.

A observação e a coleta de dados sobre o grupo aconteceu simultaneamente com o período da disciplina. A criação das categorias de usos, no entanto, foi sistematizada $a$ 
posteriori. Para a interpretação dos dados utilizamos os procedimentos indicados pela Teoria Fundamentada aplicada aos ambientes da web (FRAGOSO; RECUERO; AMARAL, 2011). Salientamos que os exemplos descritos abaixo foram escolhidos aleatoriamente de forma a ilustrar cada tipo de uso.

Também é importante salientar que na última aula duas atividades aumentaram o número de postagens no grupo. A primeira delas foi a apresentação dos projetos finais de apropriação jornalística de redes sociais e conteúdo audiovisual feita pelos grupos. Além de apresentarem seus projetos, os alunos deveriam postar comentários sobre os projetos dos colegas no próprio grupo e em seus perfis do Twitter. As apresentações também foram fotografadas e comentadas em tempo real pela professora que postava os conteúdos sobre as apresentações no grupo.

A segunda atividade foi o pedido solicitado pela professora de que os alunos postassem suas impressões sobre a condução e o uso da ferramenta grupo ao longo do semestre e que autorizassem a utilização de suas postagens e comentários para uma apresentação ao colegiado do curso de jornalismo e, posteriormente, para um artigo a ser produzido. Apesar das autorizações, optamos pelo uso apenas das iniciais dos alunos, mantendo o anonimato dos mesmos por questões de privacidade dos dados do grupo e ética.

Em uma reunião do colegiado no mês de Outubro, foi solicitado que os docentes comentassem suas práticas de sala de aula, gerando uma discussão sobre as diferenças e semelhanças entre as funcionalidades e a usabilidade das plataformas de Ensino à Distância (EAD) como o Moodle e o sistema interno de compartilhamento de arquivos Pastanet $^{\text {xii }}$, utilizadas oficialmente na universidade, e um site como o Facebook, por exemplo. Dessa forma, entendemos que a categorização desses usos também foi influenciada pelos conhecimentos anteriores à análise e pelas discussões acontecidas nessa reunião.

Em relação ao conteúdo gerado através do grupo observamos os seguintes usos:

a) Mural de recados: postagens sobre as atividades desenvolvidas em aula - material para ser acessado através do site de compartilhamento de arquivos Slideshare (www.slideshare.net), por exemplo, orientações diversas sobre as aulas e para 
organização de trabalhos em grupo, lembretes das tarefas que integravam as avaliações de Grau A e Grau B. Conforme podemos ver na imagem abaixo há uma postagem feita pela professora indicando as atividades da aula, inclusive com um link para o material publicado via Slideshare e além do habitual curtir, surge um questionamento por parte de um aluno sobre o modo como a atividade transcorreria. (FIGURA 1);

Figura 1: Exemplo de uso do grupo como Mural de Recados

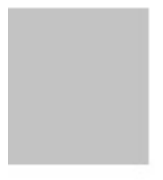

A

Aua de hoje (após a saída do Behsi http://wnw.slideshare.net/materialdeaula,introredes-sociais-9636625

Curtir - Comentar - Seguir publicaçâo * 10 de Outubro de 2011 às 20:00

$$
\text { LI curtiu isto. }
$$

Escreva um comentário...

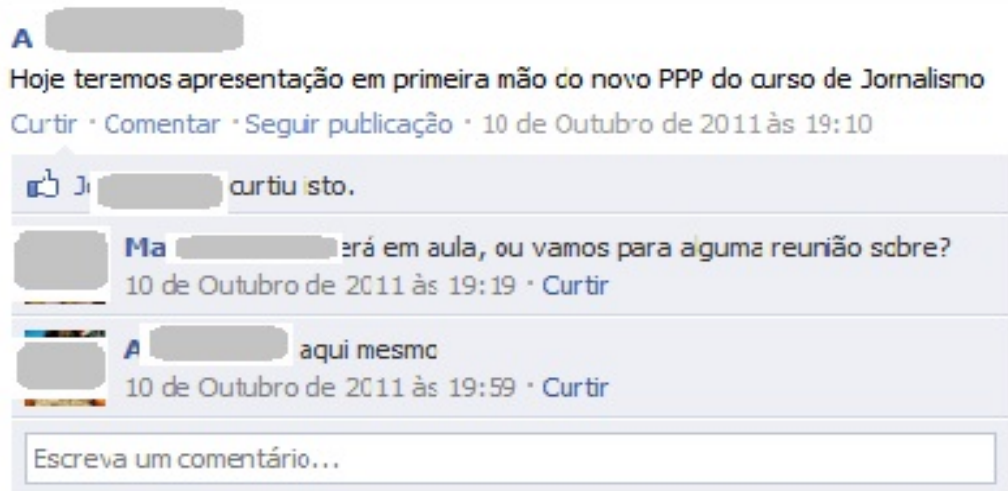

Fonte: Grupo Jornalismo

b) Postagem de links: compartilhamento de informações referentes aos conhecimentos de cibercultura e jornalismo digital, inovações na área de mídias sociais, notícias de tecnologia e até mesmo vagas de estágio em Jornalismo Digital. Na imagem abaixo (FIGURA 2), podemos ver as publicações de dois alunos relacionando links a conteúdos de sala de aula. O primeiro deles comentando um artigo de referência sobre o mercado do jornalismo digital e o segundo indicando uma matéria a respeito de um newsgame, um formato híbrido 
entre infografia animada, jornalismo e entretenimento debatido nos conteúdos da disciplina;

Figura 2: Exemplo de uso para postagem de hyperlinks

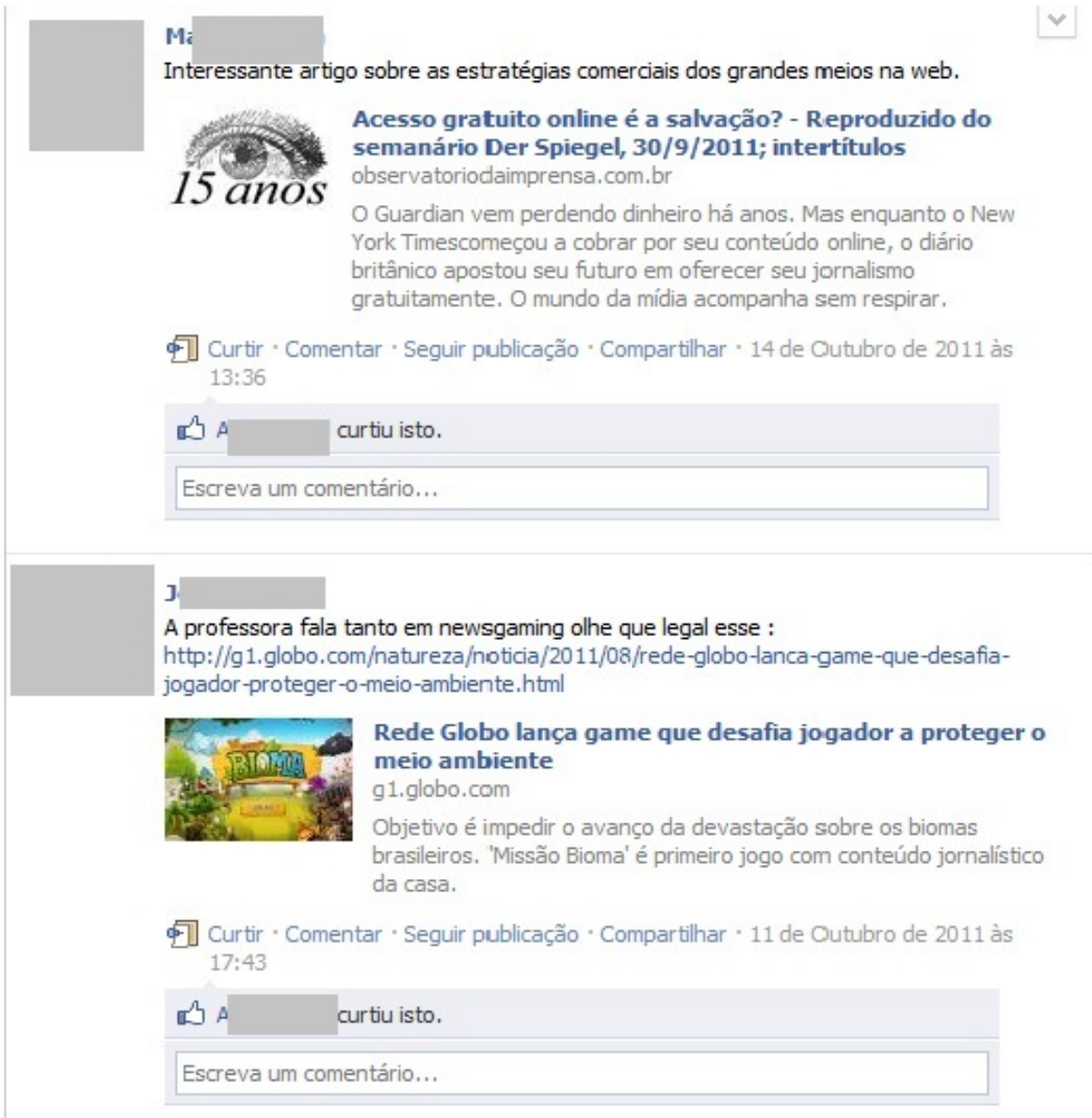

c) Postagem de trabalhos: os trabalhos elaborados para a disciplina, bem como a as atividades feitas em aula eram postados apenas no grupo, eliminando a constante troca, eventual perda de emails e o excesso de impressões. A maior parte desses trabalhos foi compartilhada através da funcionalidade da criação de documentos, bem como as notas de Grau A e Grau B (FIGURA3). Um dado interessente é o fato de que apesar de utilizarem o Facebook praticamente todos os dias, muitos alunos não sabiam como criar um documento e nem qual era sua utilidade, o que motivou trocas de informações entre professor e alunos e a 
Estudos em Jornalismo e Mídia - Vol. 9 N I - Janeiro a Junho de 2012 ISSNe 1984-6924

construção de um mini-tutorial com printscreens de como abrir um documento (FIGURA 4) aumentando o potencial de aprendizagem da ferramenta;

Figura 3: Exemplo de postagem de trabalhos de aula

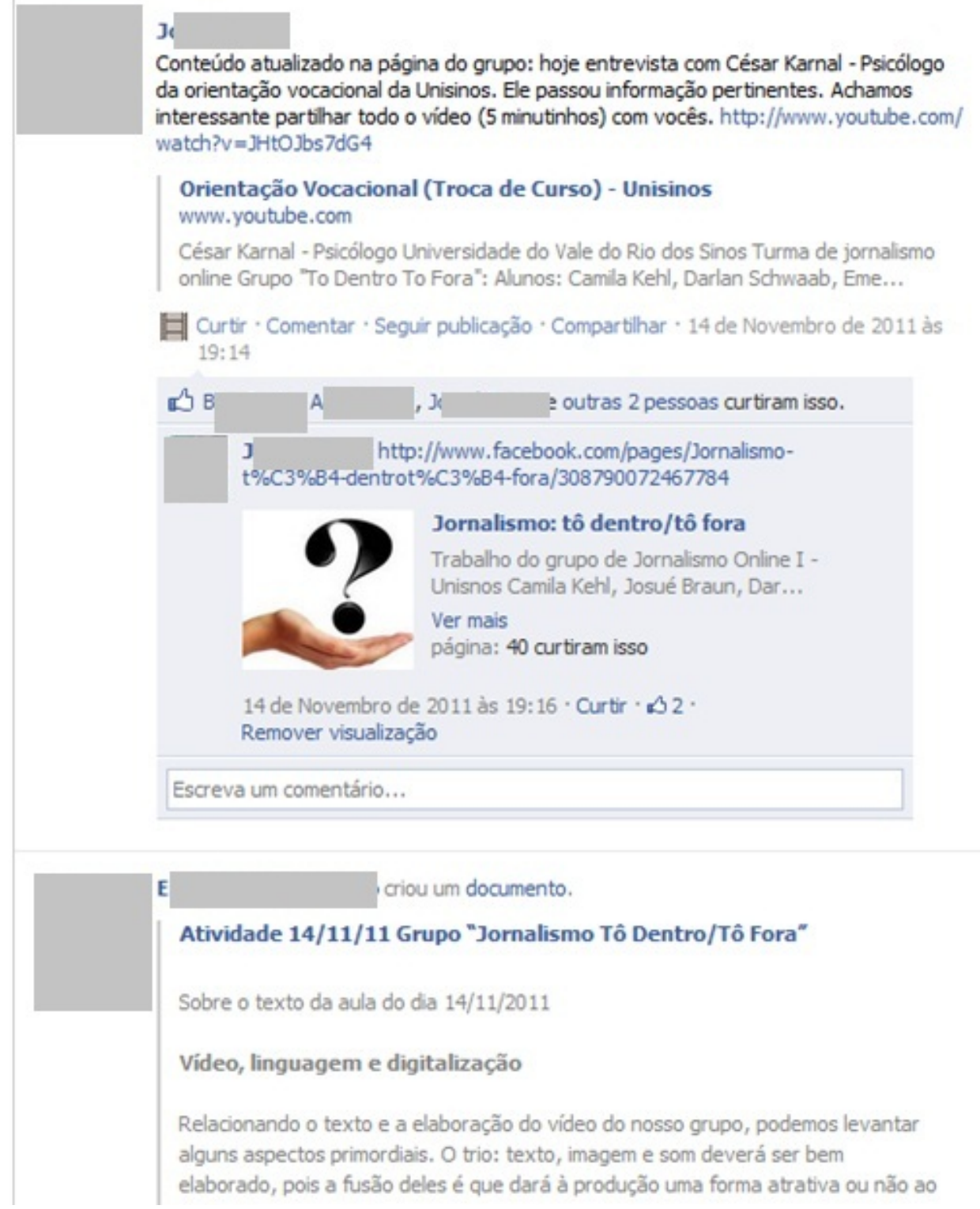

Fonte: Material de aula 
Figura 4: Tutorial de criação de documentos

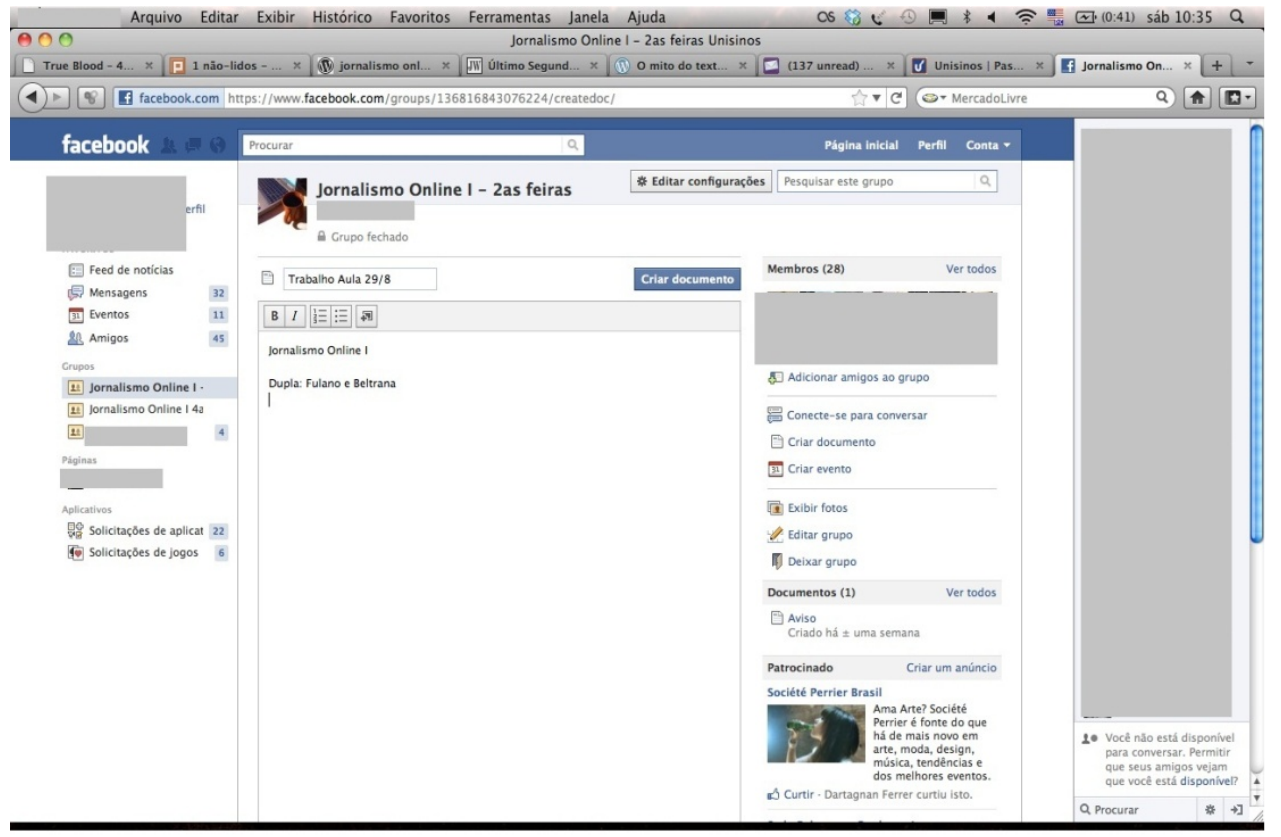

Fonte: Material de aula

d) Conversação informal: os membros do grupo utilizavam o chat do Facebook para conversas instantâneas com os demais integrantes, o que facilitava a troca de informações e dúvidas durante as aulas, possibilitando que até mesmo os estudantes que não estivessem presentes naquele dia pudessem acompanhar o conteúdo via bate-papo online. Além disso, dicas sobre atividades culturais, cursos, brincadeiras e conversas paralelas à aula apareciam no chat criando laços sociais entre os que mais conversavam, dinamizando o processo de perguntasrespostas e possibilitando interações por parte de estudantes com perfil mais tímido, que muitas vezes não faziam questões presenciais, mas se sentiam à vontade para perguntar via chat, proporcionando um ambiente complementar de sociabilidade. Essas conversas não foram documentadas e não são passíveis de recuperação, pois não ficaram memorizadas no histórico do grupo.

Ao serem questionados sobre a utilização do grupo do Facebook (no próprio grupo) nas aulas de Jornalismo Online I, os alunos em sua maioria demonstraram uma 
Estudos em Jornalismo e Mídia - Vol. $9 \mathrm{~N}^{\circ} \mathrm{I}$ - Janeiro a Junho de 2012 ISSNe 1984-6924

receptividade positiva. Entre os aspectos destacados por eles estava a agilidade da ferramenta, que possibilitava a troca de ideias de forma instantânea, na qual era possível agregar os trabalhos e atividades, servindo como espaço de interação entre os colegas e professora. Outro ponto levantado pelos estudantes foi a praticidade do uso. É preciso considerar que a maioria da turma já era usuária do Facebook, logo já estavam habituados a utilizar os grupos. Além disso, a ferramenta era uma opção mais funcional e comportava mais arquivos do que a Pastanet, sistema interno da universidade onde os professores disponibilizam de forma digital textos e materiais de aula acessados por alunos.

Para os estudantes, o grupo também funcionava como facilitador, pois a publicação das tarefas antes das aulas adiantava o processo de organização das atividades. Entre os relatos, também foi apontada a maior liberdade para a utilização didática dos recursos da ferramenta, já que a disponibilização do bate-papo online possibilitava o acompanhamento virtual das aulas por parte dos alunos que não estavam presentes em sala e que não se sentiam tão desorientados ao faltarem uma aula.

Para a professora, apesar do acúmulo de informações e da ansiedade em responder dúvidas que se avolumavam, o contato praticamente diário - de acordo com variação das postagens - com os alunos através do grupo ampliava a sala de aula para além do encontro semanal, ou seja: "a contiguidade online/offline se apresenta sob fluxos e contribui (para o bem ou para o mal) para uma expansão da sala de aula como local de aprendizado". (AMARAL, 2011, Online)

\section{Considerações finais}

A proposta desse artigo era relatar uma experiência de ensino e aprendizagem do jornalismo digital a partir das observações dos tipos de usos do Facebook em sala de aula. Com as transformações na produção das práticas e rotinas jornalísticas possibilitadas pelos processos de digitalização e pelas interações sociais dai decorrentes há um constante redesenho, e aumento dos desafios para pensar e ensinar a 
Estudos em Jornalismo e Mídia - Vol. $9 \mathrm{~N}^{\circ} \mathrm{I}$ - Janeiro a Junho de 2012

comunicação e o jornalismo digital em um ambiente tradicional como a Universidade brasileira.

Nesse sentido, o presente texto tenta apresentar algumas reflexões acerca das apropriações do Facebook através da ferramenta Grupos, já utilizado de forma cotidiana, mas agora trazido ao contexto acadêmico. Essa atividade apresenta-se como uma forma possível para amplificar o instrumental teórico e prático para a atuação profissional do jornalista nas diversas frentes que se desenham na articulação entre tecnologias da comunicação, através do desenvolvimento de habilidades técnicas e cognitivas no uso de plataformas e ferramentas e na compreensão dos processos culturais implicados nestas dinâmicas, posicionando o jornalista no centro desse debate, como mediador dos espaços sociais, para além de uma mera reprodução dos conteúdos.

A utilização de apenas uma ferramenta o grupo Jornalismo Online I - 2as Feiras evidentemente, não preenche as lacunas na formação dos profissionais e para tanto, faz-se necessária a combinação com outros elementos sejam eles de ordem tecnológica como o uso de outras plataformas como, por exemplo, o Slideshare e blogs; ou mesmo de conteúdo, como a utilização de vários tipos de materiais (audiovisuais, textuais, teóricos, práticos, etc) e de formatos de aula (expositiva, laboratório, seminários, etc). Atividades extra-curriculares como congressos, encontros ${ }^{\mathrm{xiii}}$, palestras e mesa-redondas com pesquisadores e profissionais do mercado também devem ser estimuladas.

Essa experiência pode servir para fornecer subsídios para a reflexão sobre diferentes condutas éticas e comportamentos do jornalista digital, como o perfil multimídia debatido por Salaverria (2007) e criticado por outros autores, pois:

Quando falamos do jornalista na web, tratamos de perfis diversos. O estatuto precário do repórter em tempo real, a posição de destaque ocupada pelo blogueiro e a hiperfuncionalidade do jornalista multimídia são diferentes faces de um fenômeno que busca se renovar nas diferentes maneiras de fazer jornalismo. (JORGE; PEREIRA; ADGHIRNI, 2009, p.93)

Além do perfil dos estudantes em formação e dos profissionais que chegam ao mercado é também interessante considerar para futuras pesquisas, o próprio perfil dos 
professores conforme indicado por estudo realizado por Quadros, Caetano e Amaral (2011, p.130).

Por fim, a respeito dos usos da própria ferramenta percebemos em nossa inserção que ela foi utilizada basicamente de quatro formas: mural de recados, para postagem de links, publicação de trabalhos e como meio de conversação informal alinhando aspectos pedagógicos e de sociabilidade. Assim, o Facebook, "ultrapassa os limites do espaço virtual quando torna-se também um canal de comunicação e uma extensão dos ambientes de sala de aula. (OLIVEIRA; ARAUJO, 2011, p.01)

Dessa maneira também é preciso compreender a relação docente-discente no ensino de comunicação, muito mais para uma prática de curadoria e mapeamento de temáticas, debates, conteúdos e de moderação das discussões que acontecem tanto nas aulas presenciais quanto nos ambientes digitais e em suas semelhanças e diferenças que exigem outras percepções.

Pensar nessas dinâmicas de aula e experimentá-las (que nem sempre darão certo) dá trabalho - por vezes parecendo interminável - cansa, gera ansiedade e problemas, mas também traz resultados únicos e inesperados para a troca de informações e a construção do conhecimento, muito além da ementa, dos conteúdos programáticos e de todos aqueles termos pedagógicos aos quais nos acostumamos em nossas zonas de conforto e anos de estrada. (AMARAL, 2011, Online)

Essas considerações sobre iniciativas e práticas de sala de aula, ainda que breves, indicam apontamentos sobre a complexidade cada vez maior de ensinar e aprender jornalismo no contexto da cibercultura. 


\section{Referências}

AMARAL, Adriana. Expandindo a sala de aula. Brasil, maio, 2011. [Blog]. Disponível em http://palavrasecoisas.wordpress.com/2011/05/01/expandindo-a-sala-de-aula. Acesso em jul. 2011.

AMARAL, Adriana; CARDOSO, Anelise.; JAHN, Carlos, BEHS, Edelberto, FURTADO, Thais. Projeto Político-Pedagógico do Curso de Jornalismo. Anexo à Resolução do CONSUN no. 037/2011.

Documento.

COMSCORE PRESS RELEASE. Brazil's Social Networking Activity Accelerates in the Past Year Fueled by Facebook Growth, March, 19, 2012. Disponível em $<<$ http://www.comscore.com/Press_Events/Press_Releases/2012/3/Brazil_s_Social_Networking_Acti vity_Accelerates in the Past Year $\gg$. Acesso em: 19 mar. 2012.

FRAGOSO, Suely; RECUERO, Raquel; AMARAL, Adriana. Métodos de Pesquisa para Internet. Porto Alegre: Sulina, 2011.

JORGE, Thais M.; PEREIRA, Fábio H.; ADGHIRNI, Zélia L. Jornalismo na Internet: desafios e perspectivas no trinômio formação/universidade/mercado. In: RODRIGUES, Carla. (Org). Jornalismo On-line: modos de fazer. Porto Alegre: Sulina, 2009.

MACHADO, Elias. Prefácio. QUADROS, Claudia.; CAETANO, Kati.; LARANGEIRA, Álvaro. (Orgs). Jornalismo e Convergência: ensino e práticas profissionais. Covilhã: Labcom, 2011.

OLIVEIRA, Robson; ARAÚJO, Júlio C. O Twitter como ferramenta de discussão acadêmica: possibilidades e limitações. In: Trabalho apresentado no IV Encontro Nacional de Hipertexto e Tecnologias Educacionais. Hipertexto 2011. Disponibilizado por email pelos autores. Acesso em: 27 set. 2011.

PALACIOS, Marcos. Jornalismo on-line, informação e memória: apontamentos para debate. Revista PJ: BR Jornalismo Brasileiro, edição 4, São Paulo, 2004. Disponível em:

$<<$ http://www.eca.usp.br/pjbr/arquivos/artigos4_f.htm $>>$ Acesso em: 10 jan. 2012.

PRIMO, Alex (Org.). Mapeamento do ensino de jornalismo digital no Brasil em 2010. São Paulo: Itaú Cultural, 2010.

QUADROS, Claudia; CAETANO, Kat;, AMARAL, Adriana. O ensino do jornalismo digital e as práticas de convergência: análise de disciplinas e formação docente. In: QUADROS, Claudia.; CAETANO, Kati.; LARANGEIRA, Álvaro. (Orgs). Jornalismo e Convergência: ensino e práticas profissionais. Covilhã: Labcom, 2011.

QUADROS, Claudia.; CAETANO, Kati.; LARANGEIRA, Álvaro. (Orgs). Jornalismo e Convergência: ensino e práticas profissionais. Covilhã: Labcom, 2011.

SALAVERRÍA, Ramon. La convergencia multimedia en las empresas de comunicación. Vídeo produzido na Faculdade de Comunicação da Universidade de Navarra, 2007. 
'A partir de uma abordagem culturalista, o local de fala de quem produz o debate também tem impacto sobre os resultados da pesquisa. A perspectiva dialógica entre a visão do professor e do aluno sobre um recurso de sala de aula adotada nesse artigo desenvolveu-se ao longo do semestre em debates em sala de aula e nas orientações da Iniciação Científica. Da mesma forma que ele amplia a visão de relato para alem das funcionalidades - o que funcionou na prática de ensino-aprendizagem a partir dessa plataforma - ele também nos dá uma perspectiva em diferentes níveis de compreensão do próprio jornalismo digital. Por outro lado, poderíamos argumentar limites relacionados a inserção de ambos na mesma disciplina e ambiente que constituiu o objeto analisado.

\section{ii http://www.facebook.com}

iii Desde as últimas aulas ministradas no semestre 2011/1, observou-se sistemática uma prática rotineira entre os alunos: logo ao chegarem no laboratório, o primeiro site a ser acessado ou a primeira aba aberta era a página de entrada do Facebook, que invariavelmente permanecia aberto até o período final (a aula vai das $19 \mathrm{~h} 30$ às $22 \mathrm{~h} 23$ com intervalo de 20 minutos). Enquanto anotavam a matéria ou faziam os trabalhos, muitos alunos teclavam via chat ou mandavam mensagens ou publicavam conteúdo no Facebook.

iv De acordo com os dados da ComScore o "Facebook ultrapassou o Orkut em Dezembro de 2011, assumindo a liderança como o principal destino de site de rede social no Brasil com 36.1 milhão de visitantes, subindo 192 porcento em relação ao ano anterior. O Facebook também se tornou o site de rede social no qual os usuários passam mais tempo engajados. Em média, em Dezembro de 2011, eles passam 4,8 horas por dia, sendo que em 2010 passavam apenas 37 minutos diários.”(COMSCORE PRESS RELEASE, Online) Tradução das autoras.

$\checkmark$ Nosso objetivo não é rediscutir o ensino do jornalismo digital no Brasil ou a literatura sobre o mesmo, o que mereceria atenção em um outro estudo; mas sim, inserir uma prática e um recurso pedagógico nesse âmbito e indicar algumas possibilidades e limitações de uma ferramenta como uma estratégia teórico-metodológica de ensino do jornalismo digital e de sociabilidade em rede.

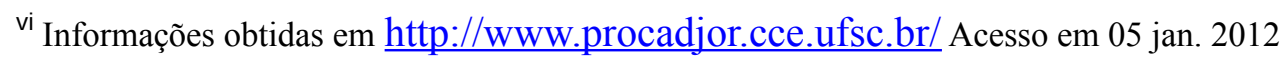

vii Informações obtidas em https://www.facebook.com/video/video.php?v=1544398803213 Acesso em 02 mar. 2012

viii Com a mudança do currículo, a partir de 2012 essa disciplina transformou-se em Jornalismo Digital, Redes e Mídias Sociais. (AMARAL et AL., 2011)

${ }^{i x}$ Segundo a ementa, a atividade acadêmica Jornalismo Online I propõe conhecimentos em cibercultura, história das mídias digitais, além de apresentar um panorama da constituição da Internet e formação da Web, que compreende o estado atual e futuro. Além disso, a disciplina introduz a teoria do hipertexto e hipermídia, trabalha com interação e construção da interatividade em ambientes digitais, elenca as particularidades do texto jornalístico em mídias digitais. Também fazem parte do conteúdo o uso de material como bancos de dados, Internet e planilhas eletrônicas em reportagem assistida por computador, formas eficientes de busca e recuperação de informação na Internet e ainda discute os valores morais e éticos do Jornalismo Online.

${ }^{\times}$Disponível em https://www.facebook.com/groups/136816843076224/. O grupo era fechado e só foram inseridos alunos regularmente matriculados na disciplina. Apos o último dia de aula, o grupo foi encerrado para postagens, mas ainda não foi excluído do Facebook por conta da escrita do artigo.

${ }^{\text {xi }}$ Aluna do Mestrado em Ciências da Comunicação da Universidade do Vale do Rio dos Sinos desde março de 2011. Bolsista da CAPES.

xii Disponível em: www.unisinos.br/pastanet

xiii Ao longo de 2011 foram realizados dois eventos regionais sobre Jornalismo Digital, organizados por professores que atuam na graduação e no PPG da Unisinos. O I Encontro Regional de Jornalismo Digital ocorreu em abril de 2011 e o II Encontro Regional de Jornalismo Digital em agosto de 2011 com participantes de várias instituições de ensino e empresas de comunicação do estado. 